\title{
SIMULAÇÃO COMPUTACIONAL DO TESTE DE CARREGAMENTO AXIAL PARA O CONCRETO
}

\author{
Guilherme A. Pianezzer, Fábio A. N. Balbo, \\ Programa de Pós-Graduação em Métodos Numéricos em Engenharia \\ 81531-990, Curitiba, PR \\ E-mail: guilherme.pianezzer@hotmail.com, andrebalbo@gmail.com
}

Liliana M. Gramani, Eloy Kavisky,

UFPR - Universidade Federal do Paraná

81531-990, Curitiba, PR

E-mail: 1.gramani@gmail.com, eloy.dhs@ufpr.br

\author{
Marcelo R. Teixeira \\ UFPA - Campus Tucuruí \\ 868464-000, Tucuruí, PA \\ E-mail: marcelorassyteixeira@gmail.com
}

\begin{abstract}
Resumo: A simulação computacional do teste de carregamento axial apresentada neste artigo foi realizada em um elemento representativo do concreto - RVE. O RVE permite representar estatisticamente o material estudado de maneira que, de acordo com as técnicas de homogeneização, propriedades encontradas neste elemento podem ser utilizadas para estimar as propriedades do material final. Este artigo, então, traz a discussão de como gerar o RVE do concreto para agregados graúdos aproximados por elipses. $O$ concreto, na escala mesoscópica, é considerado um material bifásico composto de argamassa e agregado graúdo. Para obter informações sobre os tamanhos dos agregados foi utilizada a curva granulométrica e para obter a posição de cada um dos agregados foi utilizado um algoritmo de detecção de colisão computacional entre elipses. $O$ RVE foi então sujeito a um teste de carregamento axial que foi solucionado pelo método de Galerkin livre de elementos, apresentando assim a resposta que o material possui.

Palavras Chaves: Concreto, Elemento Representativo do Material (RVE), Teste de carregamento axial.
\end{abstract}

\section{INTRODUÇÃO}

Em 2006, a Fundação Nacional de Ciência e Tecnologia dos Estados Unidos emitiu um relatório denominado [7] SBES (Blue Ribbon Panel on Simulation-Based Engineering Science) , relatando a importância do desenvolvimento da área de ciência e tecnologia, principalmente no desenvolvimento de novos materiais. Isso apenas reflete o fato que inovações metodológicas em modelagem e simulação de materiais podem trazer um aprimoramento no desenvolvimento de novos materiais e no aperfeiçoamento dos já existentes.

Esse tipo de estudo beneficia obras marcantes da sociedade, como as barragens de usinas hidrelétricas, como a Usina Hidrelétrica de Tucuruí (UHE Tucuruí) que é sustentada por mais de 20 milhões de metros cúbicos de concreto.

Para preservar este tipo de estrutura é necessário compreender e modelar modelos mecânico-matemático, também conhecidos como modelos constitutivos, que descrevem o comportamento tensão-deformação do material. Entretanto, tais modelos se baseiam em leis físicas complexas que envolvem um número elevado de variáveis, além de uma alta variabilidade estatística, visto que a resposta do material é alterada pela estrutura dele.

Ao observar o concreto, esta complexidade se torna mais evidente. Basta verificar como o concreto se comporta na escala mesoscópica. Para essa escala, o concreto é considerado como 
um material bifásico, altamente heterogêneo, composto por argamassa e agregado graúdo [2] e cada interação existente entre seus componentes deve ser processada computacionalmente.

Vários trabalhos que exploraram este desafio podem ser citados, como [1], [11], [10], [12] e mais recentemente [8]. No geral, os métodos computacionais trabalham com um elemento representativo do material (RVE) que simula, estatisticamente, uma parte do material estudado. As informações obtidas no RVE podem então ser extrapoladas para o material inteiro. Estas técnicas estão incluídas na literatura, como Teoria da homogeneização ou Teoria das propriedades efetivas.

O objetivo deste artigo é discutir como gerar computacionalmente o RVE do concreto a partir da curva granulométrica que descreve os agregados graúdos utilizados na formação deste concreto. Com a geração do RVE, este artigo apresenta a simulação realizada para o teste de carregamento axial, apresentando os mapas de deformação para várias quantidades de agregados.

Para isso, este artigo conta com informações sobre o concreto e a curva granulométrica, apresentação sobre os trabalhos relacionados em relação a geração da mesoestrutura do RVE, discussão dos métodos utilizados e resultados referentes ao teste de carregamento axial.

\section{BREVE REVISÃO DE LITERATURA 2.1. Características do concreto}

O concreto é um material que apresenta uma boa relação custo-benefício, pois apresenta uma boa durabilidade e resistência [12]. Na construção civil, ele é amplamente utilizado nas fundações, em colunas, em vigas, em lajes, em paredes e em outros elementos. Dentre os seus pontos positivos pode-se citar a excelente resistência à água, além da facilidade com a qual elementos estruturais de concreto podem ser obtidos e a sua rápida disponibilidade para o uso.

O concreto é um material poroso, heterogêneo, que pode ser estudado em diferentes escalas de trabalho[9]. Neste estudo será considerada a escala mesoscópica, que é uma escala com dimensões maiores que as das moleculares (De modo que o domínio possui propriedades macroscópicas), mas com dimensões menores que a dimensão macroscópica [8].

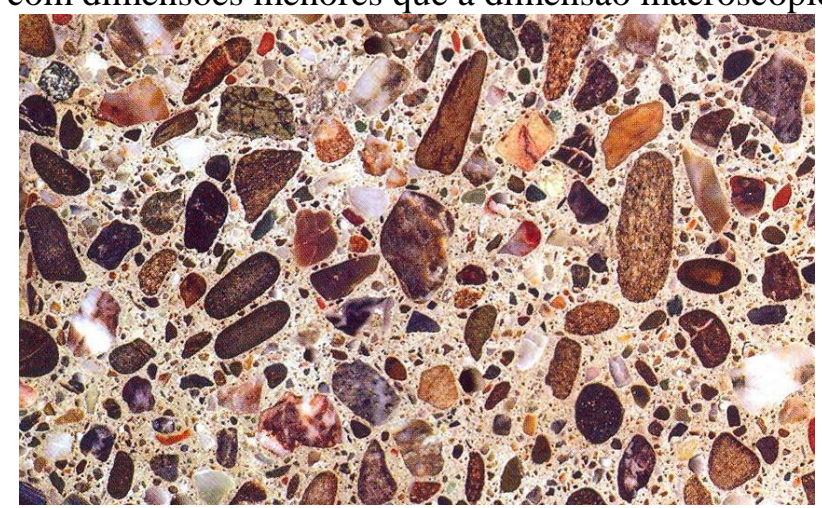

Figure 1: Heterogeneidade do concreto (Mehta, 2008)

Quando analisada a mesoestrutura do concreto percebe-se a presença de dois constituintes: A pasta de cimento endurecida - conhecida como argamassa - e as partículas de agregado graúdo, como podem ser observadas na Figura 1. Numa análise mais aprofundada também percebe-se a presença de vazios e defeitos de aderência que justificam a heterogeneidade do concreto.

Para estudar o comportamento do concreto é preciso lidar com esta heterogeneidade e para isso surge a necessidade de criar um elemento representativo do concreto (RVE). Com o RVE é possível estudar as tensões e deformações, resultantes dos efeitos que o concreto está sujeito, como a retração, a fluência e as tensões de carregamento. 
Para modelar o RVE baseia-se na curva granulométrica dos agregados graúdos presente no concreto.

\subsection{Curva granulométrica do agregado graúdo}

Segundo [6], a curva granulométrica de um solo é uma função de distribuição de partículas do solo. Como todo o solo apresenta uma alta variabilidade de partículas, em diferentes tamanho e em proporções variadas, a curva granulométrica ajuda a descrever melhor o material estudado. Para obter tal função existem técnicas como peneiramento (Para amostras secas) ou sedimentação (Para o meio líquido).

O objetivo do peneiramento é separar as partículas presentes no solo em relação a seus tamanhos. Para isso o teste consiste de uma série de peneiras de abertura de malha conhecidas que, ao serem utilizadas, permite determinar a porcentagem em peso retida ou passante em cada peneira.

Estudar o solo a partir da sua curva granulométrica permite um melhor aproveitamento de cada material em utilizações específicas. O mesmo vale para os agregados graúdos presentes no concreto. Por exemplo, para gerar o cimento, agregados finos são utilizados, pois diminuem os vazios presentes na mesoestrutura. Dessa maneira, gera-se um material com sua permeabilidade reduzida e com uma capacidade maior em resistir a reações químicas indesejáveis. Para gerar o concreto utilizado em estradas, por exemplo, é necessário utilizar um agregado que apresente uma curva granulométrica com agregados bem graduados, resultando num desgaste menor na quantidade de concreto [8].

\subsection{Geração da mesosestrutura do concreto}

O cálculo das tensões que influencia no comportamento do concreto em nível mesoscópico requer a geração de uma estrutura de agregados graúdos, onde a forma, o tamanho e a distribuição dos agregados simulam um concreto real do ponto de vista estatístico.

Segundo [12], a geração da configuração aleatória de partículas agregadas deve satisfazer as características básicas do material real. Com este objetivo, a distribuição deve ser tal que as partículas sejam o máximo possível macroscopicamente homogêneo no espaço. A idéia principal deste trabalho é escolher partículas de agregado graúdo de uma fonte, cuja distribuição segue uma certa curva representativa do material e além disso alocar cada partícula seguindo algumas regras de posicionamento, como, por exemplo, não haver intersecção entre os agregados.

Cada forma das partículas depende do tipo de agregado escolhido. Vários métodos de caracterizar a geometria dos agregados já foram publicados, como [11] e [10]. Em trabalhos mais recentes, como [12] e [8], cada agregado teve sua forma aproximada pela de um círculo ou pela de uma esfera. Nesses trabalhos, os raios médios dos agregados também foram obtidos a partir da curva granulométrica.

Em relação a geração da mesoestrutura do concreto este trabalho traz uma mudança ao aproximar a forma de cada agregado por elipses.

\section{MATERIAIS E MÉTODOS 3.1 Obtenções do tamanho dos agregados}

A distribuição dos agregados, dados pela sua curva granulométrica, é representada por uma lista de valores discretos para cada abertura da peneira. A tabela 1 mostra um exemplo de um ensaio realizado para um tipo de agregado, que foi adotado neste trabalho. 
Tabela 1: Resultado da análise de peneiramento [12]

\begin{tabular}{ll|l}
\hline $\begin{array}{l}\text { Abertura da peneira } \\
(\mathrm{mm})\end{array}$ & Porcentagem total retida \\
\hline 12.70 & & 0 \\
9.50 & & 23 \\
4.75 & & 74 \\
2.36 & & 100 \\
\hline
\end{tabular}

Sendo $P(d)$ a porcentagem total retida na peneira de diâmetro $d$, pode-se calcular a área do material reservado para a seção específica entre duas peneiras por:

$$
A_{p}\left[d_{g}, d_{g+1}\right]=\frac{P\left(d_{s+1}\right)-P\left(d_{g}\right)}{P\left(d_{\max }\right)-P\left(d_{\min }\right)} a_{p} A
$$

Onde $A_{p}\left[d_{g}, d_{g+1}\right]$ é a área de material reservado para a seção específica entre as peneiras $d_{g} \mathrm{e}$ $d_{g+1}$, A é a área total do RVE e $a_{p}$ é a fração de área que os agregados ocupam. $a_{p}$ é um parâmetro importante do programa que pode ser moldado a partir de algumas grandezas físicas do concreto, como densidade e massa.

Os parâmetros que definem as elipses nesta simulação são:

$\theta_{\mathrm{i}}:$ Ângulo que o semi-eixo maior faz com a reta que une o centro das duas elipses

$A_{\mathrm{i}}, B_{\mathrm{i}}$ : Semi-eixo maior e semi-eixo menor, respectivamente

$C_{i^{\sharp}}$ Centro da elipse $i$.

Cada elipse é armazenada através de 5 componentes. Duas componentes com a posição do centro, duas para o tamanho do semi-eixo maior e menor e uma última componente com o ângulo que o semi-eixo maior faz com o sistema de referências.

O algoritmo desenvolvido para realizar a leitura da curva granulométrica e extrair informações sobre os tamanhos dos agregados graúdos presentes na espécie estudada pode ser visto, detalhadamente, em [5], onde o autor descreve as dificuldades encontradas e as aproximações e hipóteses escolhidas.

\subsection{Geração do RVE do concreto}

Após gerar computacionalmente o tamanho de cada agregado surge a necessidade de posicioná-los. Para isto são consideradas duas hipóteses. A saber: (1) De que os agregados devem estar inteiramente contidos no domínio do concreto e (2) que não deve existir intersecção entre os agregados.

Com estas aproximações, o problema se reduz a outro, conhecido na literatura como detecção de colisão. Essa classe de problemas são referentes aqueles que buscam inferir sobre a existência de intersecção entre duas ou mais figuras, computacionalmente.

Para detectar a existência destas intersecções é necessário ter um procedimento que, ao adicionar um novo agregado na matriz de argamassa, verifique se há intersecção entre os elementos. Para realizar este teste, foi referenciado o trabalho de [3] que mostra que a existência ou não de colisão entre duas elipses pode ser verificada a partir do estudo dos sinais das raízes de uma equação, a qual chamaram, equação característica. A Figura 2 mostra o comportamento da equação característica para alguns casos de elipse.

A partir deste algoritmo, pode-se verificar se há intersecção entre os agregados e por fim completar os parâmetros necessários para localizar as elipses. Discussões detalhadas sobre como obter as raízes da equação característica e sobre o algoritmo desenvolvido para a geração do RVE também estão presentes em [5]. 

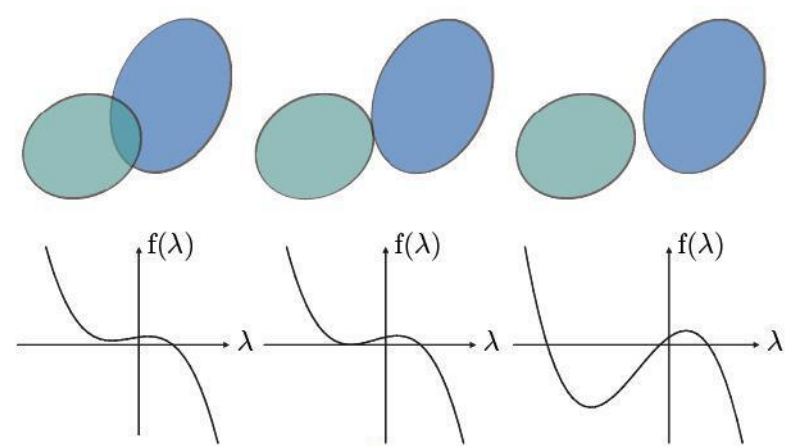

(a)

(b)

(c)

Figura 2: Comportamento da equação característica [3]

\subsection{Teste de carregamento axial}

Após a geração do elemento representativo do concreto, sujeitou-se o RVE a um teste de carregamento axial. Na literatura, o cálculo das tensões e deformações que o RVE estaria sujeito já foi resolvido pelo método dos elementos finitos ([12], [11], [10]) ou através do método de Galerkin livre de elementos [8].

Para este trabalho foi utilizado o método de Galerkin livre de elemento, programado através do software MatLab versão R20100. Neste caso, as propriedades dos componentes utilizadas foram aquelas encontradas em [8] e estão na Tabela 2.

\begin{tabular}{l|lr|ll}
\multicolumn{5}{c}{ Tabela 2: Características dos componentes [8] } \\
\hline & $\begin{array}{l}\text { Módulo } \\
\text { Elasticidade }\end{array}$ & de & Coeficiente & de \\
& MPa) & Poison & \\
Argamassa & $3 \times 10^{4}$ & & 0,30 \\
Agregado & $5 \times 10^{6}$ & & 0,40 \\
Graúdo & & & & \\
\hline
\end{tabular}

Neste caso, foi realizado um ensaio de compressão axial com deslocamento prescrito na fronteira essencial e deslocamento nulo na fronteira natural.

\section{RESULTADOS}

O tamanho do concreto utilizado foi fixado em $10.000 \mathrm{~mm}^{2}$, de forma quadrada com lados de $100 \mathrm{~mm}$. A Figura 3 e 4 apresentam o RVE gerado para 40 e $60 \%$ de fração volumétrica de agregados, respectivamente. Dificilmente o concreto encontrado tem uma fração volumétrica acima dos 60\%, o que mostra que este algoritmo pode ser utilizado nos mais diferentes casos.

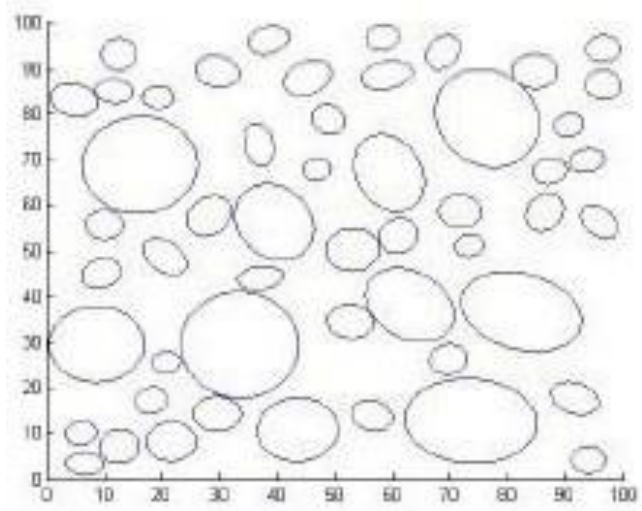

Figura 3: RVE gerado com $a_{p}=40 \%$. 


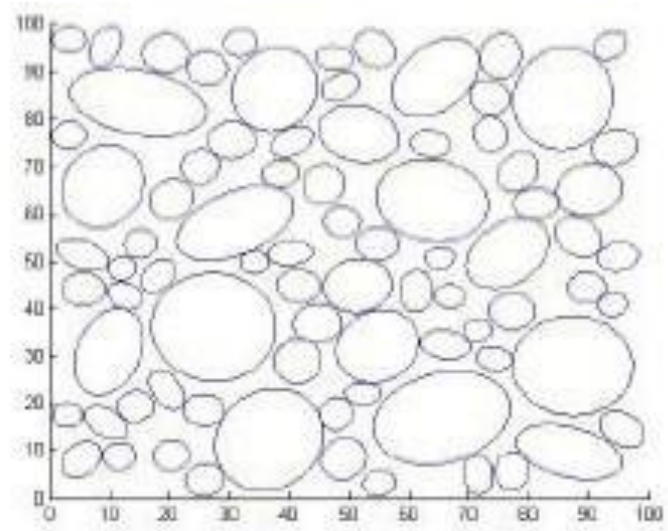

Figura 4: RVE gerado com $a_{p}=60 \%$

Com o RVE gerado, submeteu-o a um teste de carregamento axial. Como o algoritmo possui um tempo computacional muito elevado, foram construídos o mapa da deformação para uma certa quantidade de agregados. A Figura 5 e 6 mostram o mapa de deformação gerado para um RVE com 10 e 16 agregados, respectivamente.

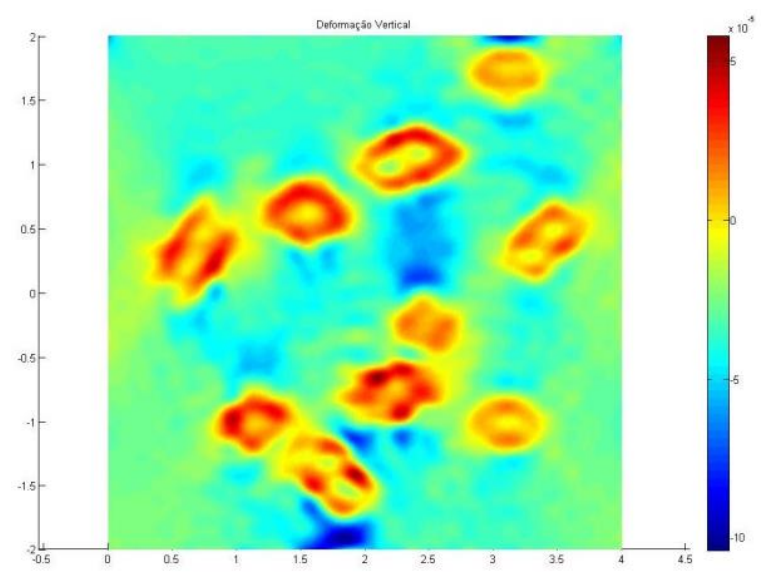

Figura 5: Mapa de deformação para RVE com 10 agregados.

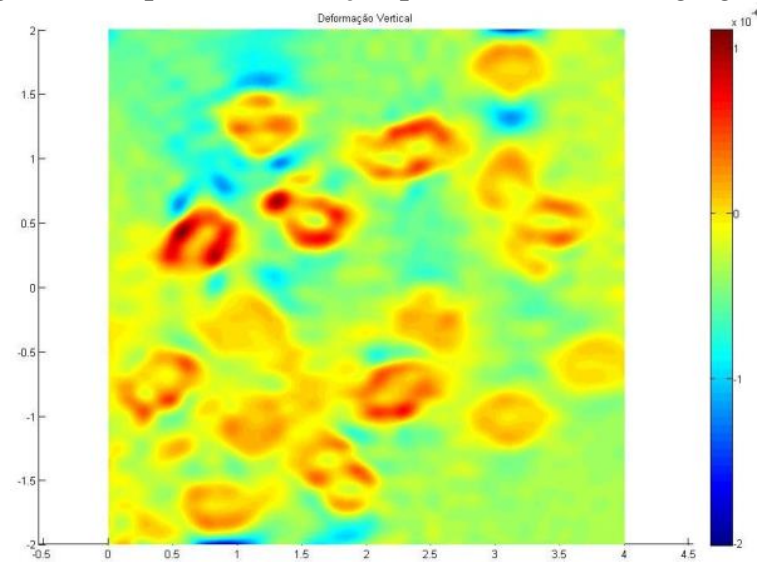

Figura 6: Mapa de deformação para RVE com 16 agregados.

Tais mapas de deformação nos permitem observar a influência dos agregados na estrutura do concreto. A resistência do concreto ideal é obtida a partir da combinação da resistência dos dois materiais que o constituem: a argamassa e os agregados graúdos. Como os agregados graúdos possuem uma resistência a compressão maior que a argamassa, percebe-se que o material como um todo tem sua resistência melhorada quando possui uma concentração maior de agregados graúdos. 


\section{CONCLUSÃO}

O objetivo deste artigo foi descrever o estudo realizado sobre a obtenção das propriedades do concreto submetido a carregamento axial. Este trabalho faz parte de um trabalho maior que busca encontrar as propriedades efetivas do concreto através de técnicas de homogeneização e multi-escala. As técnicas de homogeneização clássica utilizam um RVE, pois ele permite expandir as propriedades encontradas para o material como um todo.

Utilizar o RVE para verificar as tensões envolvidas é uma de suas principais utilidades, pois ao saber que as tensões limites estão sendo ultrapassadas, pode-se caracterizar o dano envolvido no material.

Além disto, para que estes modelos se aproximem ainda mais da realidade, faz-se necessário uma continuação deste trabalho, modelando RVE's tridimensionais, por exemplo, que representem melhor a heterogeneidade do concreto.

\section{Referências}

[1] BAZANT, Z. P. Random particle model for fracture of aggregate of fiber composites. J. Engng Mech. V. 116, n.8, p. 1686-1705, 1990.

[2] CALlister, W. D. Fundamentos da Ciência e Engenharia de Materiais. São Paulo: Editora LTC, 2006.

[3] CHOI, Y. et al. Continuous collision detection for elliptic disks. HKU CS Tech Report, 2005.

[4] MEHTA, P. e MONTEIRO, P. Concreto - Microestrutura, propriedades e materiais. São Paulo: IBRACON, 2008.

[5] PIANEZZER, G. A. et al. Um algoritmo para geração do elemento representative do concreto com agregados graúdos em formato elíptico, Revista Sodebras, v. 8, n.86, p.11-15.

[6] PINTO, C. Curso básico de mecânica dos solos. São Paulo: Oficina de textos, 2008.

[7] SCIENCE, S-B.E. Report of the National Science Foundation Blue Ribbon Panel (NSF). [S.1.], 2006.

[8] TEIXEIRA, M. R. A contribution to the numerical modeling of the heterogeneity of concrete with the elements free Galerkin method. Tese (Doutorado), São Paulo, 2011.

[9] TULIO, B. N. Experimental analysis of fracture processes in concrete. Revista Brasileira de Ciências Mecânicas, v.23, p. 545-550, 2001.

[10] WANG, Z. et al. Mesoscopic study of concrete i: generation of random aggregate structure and finite element mesh. Comput, v. 70, p. 533-544, 1999.

[11] WITMMANN, F. et al. Simulation and analysis of composite structures. Mater, Sci, Engng, v. 68, p.239-248, 1984.

[12] WRIGGERS, P. e MOFTAH, S. O. Mesoscale models for concrete: Homogeneization and damage behavior. Elsevier, v. 42, p. 623-636, 2006. 